\title{
PENGARUH MODEL LATIHAN MODIFIKASI BOLA GANTUNG TERHADAP KEMAMPUAN SERVIS ATAS PUTRA EKSTRAKURIKULER SMKN 3 KOTA BENGKULU
}

\author{
Hendri Jaya \\ Universitas Bengkulu \\ Hendrihajidin@gmail.com \\ Bayu Insanistyo \\ Universitas Bengkulu \\ Sofino \\ Universitas Bengkulu
}

\begin{abstract}
Abstrak
Penelitian ini bertujuan untuk mengetahui pengaruh model latihan modifikasi bola gantung terhadap kemampuan servis atas bola voli putra ekstrakulikuler SMK N 3 Kota Bengkulu. Penelitian ini merupakan penelitian Quasi Eksperimental Design dengan jumlah subjek adalah 20 orang siswa. Hasil penelitian ini didapatkan kenaikan nilai standat deviasi dari hasil pre-test sebesar 4,161 terhadap hasil post-test sebesar 6,012. Hasil uji normalitas di dapatkan nilai Asymp. Sig pre-test dan post-test lebih besar dari 0,05 yang berarti hipotesis diterima. Dalam uji homogenitas didapatkan hasil signifitasi hitung sebesar 0,025 lebih besar dari 0,05 yang berarti hipotesis diterima. Hasil uji-t diperoleh nilai t hitung -3,876 lebih kecil dari 0,05, maka hipotesis diterima. Berdasarkan hasil penelitian yang telah diperoleh dengan analisis dan pengujian hipotesis maka dapat ditarik kesimpulan sebagai berikut: Terdapat Pengaruh yang signifikan dari model latihan modifikasi bola gantung terhadap kemampuan servis atas putra ekstrakurikuler bila voli siswa SMK N 3 Kota Bengkulu.
\end{abstract}

Kata Kunci: Modifikasi Bola Gantung, Servis Atas, Bola Voli.

\begin{abstract}
This study aims to determine the effect of the model of hanging ball modification on the service ability of volleyball extracurricular participants SMKN 3 Kota Bengkulu. This research is Quasi Experimental Design research by using One-Group PretestPosttest Design with the number of subject is 20 students. the result of this research concludes that there is an increase of standard deviation value from pre-test result 4,161 to post-test result equal to 6,012. Normality test results in getting Asymp value. Sig pre-test and post-test is greater than 0.05 which means the hypothesis is accepted. In homogeneity test, the result of calculation mean 0,025 is greater than 0.05 which means the hypothesis is accepted. The t-test results obtained $t$ value arithmetic -3.876 smaller than 0.05, then the hypothesis accepted. Based on the results of research that has been obtained with the analysis and hypothesis testing it can be drawn conclusion as follows: "There is a significant influence of the model of hanging ball modification on the service ability of extracurricular participants when the student volunteers SMK N 3 Kota Bengkulu".
\end{abstract}

Keywords: Mods. Hanging Ball, Top Service, Volley Ball. 


\section{PENDAHULUAN}

Saat ini bola voli merupakan salah satu olahraga yang berkembang dan populer di Indonesia, perkembanganya bisa dilihat dari tingginya animo masyarakat bermain bola voli baik usia muda maupun usiatua. Permainan bola voli ini tidak hanya dikenal dengan olahraga yang memerlukan banyak tenaga, tetapi juga sebagai kegiatan untuk rekreasi dan silahturahmi masyarakat baik dilingkungan sekolah, perkantoran, dan masyarakat luas.

Olahraga bola voli menjadi salah satu olahraga yang menyenangkan karena olahraga ini dapat beradaptasi dengan berbagai kondisi yang mungkin timbul di dalamnya, seperti tempat permainan yang dapat dilakukan didalam dan diluar ruangan. Permainan ini dapat dimainkan berapapun jumlah pemainnya, dari yang berjumlah dua orang (voli pantai) sampai enam orang, dapat dinikmati segala usia dan tingkat kemampuan, permainanya menarik bagi yang menonton, dimainkan dengan peraturan yang mudah dipahami, dan memerlukan sedikit perlengkapan.

Untuk dapat bermain bola voli putraekstrakurikuler terlebih dahulu harus bisa menguasai teknik-teknik dasar bermain bola voli terlebih lagi jika siswa ingin mencapai prestasi yang baik. Teknik dasar permainan bola voli pada awalnya amat sederhana, yang bertujuan untuk memantulkan bola sehingga melewati atas jaring kelapangan lawan sama sekali tidak ada tujuan memainkan bola agar dapat melewati jaring dan pihak pemain di seberang jaring mengalami kesulitan untuk mengembalikannya (Nuril Ahmadi, 2007:14).

Perkembangan tersebut mudah dipahami karena bola voli dimainkan semata-mata dimainkan untuk tujuan rekreasi agar diperoleh kesenangan dan kegembiraan namun pada perkembangan nya permainan bola voli menjadi olahraga yang kompetitif.
Oleh karena itu penguasaan keterampilan memainkan bola dalam permainan bola voli menjadi tuntutan utama. Teknik ini mempunyai bentuk idealnya sendiri dengan bentuk serta aturan gerakan yang khas. Tetapi bentuk ideal ini dapat kita modifikasi sendiri sesuai dengan kebutuhan masing-masing. (Nuril Ahmadi, 2007:20-31) menjelaskan bahwa teknikteknik dalam permainan bola voli meliputi: 1) Servis; 2) Pasing; 3) Bendungan (Block); dan 4) Smash (Spike).

Menurur (Pardijono dkk, 2011:19) Servis adalah upaya memasukan bola kedaerah lawan dengan cara memukul bola mengnakan satu tangan atau lengan oleh pemain baris belakang yang dilakukan daerah servis. Pada awalnya servis hanya merupakan pukulan pembukaan untuk memulai suatu permainan.

Jenis servis lainnya adalah servis atas atau servis dengan melambungkan bola keatas depan kepala. Servis jenis ini akan menjadi serangan yang mematikan apa bila teknikmemukul dan kekuatan pukulan dilakukan dengan baik karena laju bola sangat cepat dan keras sehingga sulit untuk diterima pihak lawan. Suatu tim akan mendapatkan keuntungan apa bila anggota tim dapat menguasai lebih dari satu jenis servis dengan tingkat keberhasilan yang konsisten. Melalui servis yang berbeda-beda akan membuat lawan menanti dengan terus menduga-duga servis apa yang akan dilakukan.

Bila setiap pemain melakukan servis dalam suatu tim menguasai jenis servis yang berbeda, maka tim tersebut dapat memperoleh keuntungan secara strategis karena membuat lawan selalu dalam kebingungan. Dalam hal ini peran seorang pelatih sangat menjadi faktor penting dalam penentu keberhasilan siswa dalam menguasai teknik-teknik bermain bola voli, maka dari itu pelatih harus memilih metode dan program latihan yang tepat dan baik sesuai dengan karakeristik siswa yang dilatih. 
Dalam observasi yang dilakukan di SMKN 3 Kota Bengkulu terdapat beberapa permasalah dilapangan. Permasalahan yang terjadi pada putra ekstrakurikuler adalah sulitnya membuat bola menyeberangi net hal itu dikarenakan siswa kurang menguasai teknik gerakan servis atas yang baik dan benar. Posisi badan, lengan yang tidak benar dan perkenaan telapak tangan pada saat memukul bola membuat tidak adanya kekuatan pukulan sehingga bola tidak menyeberangi net. Selain itu bola yang dipukul juga mempunyai arah yang beragam ada yang melenceng kesamping kiri, samping kanan, dan tidak menyebrangi net.

Penguasan teknik servis yang tidak baik akan berdampak pada jalannya permainan dan prestasi yang dicapai. Dari permasalah yang ditemukan pada putraekstrakurikuler bola voli di SMKN 3 Kota Bengkulu ini membuat peneliti ingin memberikan solusi berupa latihan dengan menggunakan bola digantung dengan harapan dapat meningkatkan kemampuan servis atas bola voli pada peserta ekstrakurikuler di SMKN 3 Kota Bengkulu. Atas latar belakang yang telah diuraikan tersebut, peneliti mengangkat permasalahan "Pengaruh Model Latihan Modifikasi Bola Gantung Terhadap Kemampuan Servis Atas Bola Voli Peserta Ektrakurikuler SMKN 3 Kota Bengkulu"

\section{METODE}

Penelitian ini merupakan penelitian Quasi Eksperimental Design yaitu dengan menggunakan One-Group Pretest-Posttest Design. Menurut Sugiyono, (2016:74), pada one group pretest-postest design terdapat pretest $\left(\mathrm{O}_{1}\right)$ sebelum diberi perlakuan. Maka hasil perlakuan dapat diketahui lebih akurat, karena dapat membandingkan dengan keadaan sebelum diberi perlakukan. Penelitian ini akan dilaksanakan di SMK N 3 Kota Bengkulu, karena bertempat dengan tempat saya mengajar/melatih ektrakurikuler sehingga peneliti telah mengamati bagaimana aktivitas belajar dilokasi penelitian tersebut. Sesuai dengan permasalahan yang hendak di teliti maka dalam penelitian ini yang akan menjadi populasi adalah seluruh putra ektrakurikuler SMKN 3 Kota Bengkulu berjumlah 20 orang.

Teknik pengambilan sampel dalam penelitian ini menggunakan teknik purposive sampling. Artinya teknik pengambilan sampel dilakukan secara sengaja sesuai dengan persyaratan sampel yang di tentukan. Berdasarkan teknik sampel di atas maka sampel dalam penelitian ini adalah putra ektrakurikuler bola voli SMKN 3 Kota Bengkulu yang berjumlah 20 orang.

Variabel bebas merupakan variabel yang mempengaruhi atau yang menjadi sebab perubahanya atau timbulnya variabel dependen (terikat). Pada penelitian ini variabel bebas (X) yaitu model latihan modifikasi bola gantung. Sedangkan Variabel trikat merupakan yang dipengaruhi atau yang menjadi akibat, karena adanya variabel bebas. Pada penelitian ini yang akan menjadi variabel terikat (Y) yaitu kemampuan ketepatan servis atas bola voli SMKN 3 Kota Bengkulu.

Pengumpulan data terlebih dahulu di lakukan dengan pengukuran dengan pengujian tes awal (pre-test), diikuti dengan memberikan treatment atau stimulus kedalam kelompok yang diteliti,dan di akhiri dengan mengukur kembali variabel dependen setelah diberikan stimulus (posttest) (prasetyo dan jannah dalam marcelina, 2015: 159), tes awal bertujuan untuk mengetahui data awal kemampuan servis atas sebelum kemampuan servis atas setelah sampel mendapatkan perlakuan. Tes akhir bertujuan untuk mengetahui peningkatan kempauan servis atas setelah sampel mendapatkan perlakuan selama satu setengah bulan atau 16 kali pertemuan dangan frekuensi latihan 3 kali dalam seminggu.

Sedangkan Instrumen penelitian adalah suatu alat yang digunakan mengukur fenomena alam maupun sosial yang di amati, secara spesifik semua fenomena ini disebut 
variabel

penelitian.

Sugiyono

(2016:114).Instrumen yang digunakan untuk mengumpulkan data dalam penelitian ini menggunakan tes kemampuan servis atas dengan validitas 0,625 dan reabilitas 0,768 (Fauziah: 2011).

Analisis data yang digunakan peneliti menggunakan paired samples test, yaitu dengan membandingkan hasil pre-test dengan post-test .Sebelum dilakukan uji hipotesis, terlebih dahulu mencari normalitas dan homogenitas data untuk mendapat keputusan menerima atau menolak hipotesis pada taraf signifikan $5 \%$.

\section{HASIL DAN PEMBAHASAN}

\section{Hasil}

Data yang dikumpulkan dan di analisis adalah data hasil Tes kemampuan servis atas putra ekstrakurikuler bolavoli SMK N 3 Kota Bengkulu, yang diperoleh dari subyek penelitian yang berjumlah 20 responden yang diberikan perlakuan latihan dengan memukul bola digantung. Sebelum diberikan perlakuan dilakukan tes awal untuk mengetahui kemampuan servis atas awal siswa sebelum diberi latihan, setelah itu diberi perlakuan selama kurang lebih selama 16 kali pertemuan, kemudian dilakukan tes akhir untuk mengetahui apakah ada peningkatan kemampuan servis atas. Agar penelitian lebih mudah pengerjaannya, maka dari kedua variabel tersebut dilambangkan dalam X1 untuk kelompok Pre-Test dan X2 untuk kelompok Post Test. Hasil analisis deskriptif data penelitian.

\section{Uji Normalitas}

Pengujian normalitas mengunakan uji Chi Square. Dalam uji ini akan menguji hipotesis sampel berasal dari populasi berdistribusi normal, untuk menerima atau menolak hipotesis dengan membandingkan harga Asymp. Sig dengan 0,05. Kriterianya Menerima hipotesis apabila Asymp. Sig lebih besar dari 0,05, apabila tidak memenuhi keriteria tersebut maka hipotesis ditolak.

\begin{tabular}{c|c|c|c}
\hline No & Variabel & Asymp. Sig & Kesimpulan \\
\hline 1 & Pre Test & 0.258 & Normal \\
\hline 2 & Post Test & 0.111 & Normal \\
\hline
\end{tabular}

Dari tabel diatas harga Asymp. Sig dari variabel pretest sebesar 0,258 dan pos test sebesar 0,111. Karena harga Asymp.Sig dari kedua variabel semuanya lebih besar dari 0,05 maka hipotesis yang menyatakan sampel bedasarkan dari populasi yang berdistribusi normal diterima.

b. Uji Homogenitas

Uji homogenitas menggunakan uji $\mathrm{F}$ dengan derajat kebebasan dan taraf signifikansi $a=0,05$ pada tabel berdistribusi F. Hasil yang diperoleh adalah:

Tabel 6 Uji Homogenitas

\begin{tabular}{c|c|c|c}
\hline F hitung & $F(0,05)(1,38)$ & Sig. & Kesimpulan \\
\hline 3.876 & 4.10 & 0.027 & Homogen \\
\hline
\end{tabular}

Dari perhitungan diperoleh harga Fhitung sebesar 3,876, sedangkan Ftabel ( $\alpha=$ 0.05) (1/38) sebesar 4,10. Karena harga Fhitung lebih kecil dari harga Ftabel, maka hipotesis yang menyatakan varians dari variabel yang ada sama diterima. Cara yang kedua dengan membandingkan harga signifikansi hitung dengan 0,05 diperoleh hasil signifikansi hitung sebesar 0,027 $(>0,05)$. Dengan demikian dapat ditarik kesimpulan dari hasil uji homogenitas bahwa varians populasi homogen.

\section{Uji Tertulis}

Analisis data dilakukan dengan uji-t pada data kelompok pretest dan kelompok posttest hasil pengukuran tes kemampuan servis atas. Dalam uji ini akan menguji hipotesis adakah pengaruh modifikasi bola yang di gantung dapat meningkatkan kemampuan servis atas putra ekstrakurikuler bolavoli SMK N 3 Kota Bengkulu. Untuk menerima atau menolak hipotesis dengan membandingkan harga $t$ hitung dengan harga $t$ tabel. Kriterianya adalah menerima hipotesis apabila harga t hitung lebih kecil

Tabel1. Uji Normalitas 
dari harga $t$ tabel dengan derajat kebebasan $(\mathrm{dk})=\mathrm{n}-1$, dan taraf kesalahan 0,05.

Untuk mengetahui pengaruh model latihan bola gantung dapat meningkatkan kemampuan servis atas peserta ekstrakurikuler bolavoli SMK N 3 Kota Bengkulu digunakan uji-t dua sampel sama atau Paired. Sampel $t$ test. Hasil uji-t ditunjukkan pada tabel berikut.

Tabel 7. Rangkuman hasil uji t

\begin{tabular}{l|c|c|c|c}
\hline Kelompok & $\begin{array}{c}\text { Rata- } \\
\text { rata }\end{array}$ & $T_{\text {hitung }}$ & $t(0,05)(19)$ & Sig \\
\hline Pre Test & 8.5000 & 3.044 & 1.729 & 0.007 \\
\hline Post Test & 12.4000 & &
\end{tabular}

Hasil uji-t diperoleh nilai $t$ hitung sebesar $-3,044$ dan nilai t tabel pada dk $(0,05)$ (19) sebesar 1,729 dengan tingkat signifikansi sebesar 0,000. Oleh karena nilai t hitung lebih besar dari t tabel $(-3,044<1,729)$, maka dapat disimpulkan bahwa terdapat pengaruh latihan memukul bola digantung dapat meningkatkan kemampuan servis atas putra ekstrakurikuler bolavoli SMK N 3 Kota Bengkulu. Berdasarkan tabel di atas dapat diketahui bahwa nilai rata-rata pretest adalah sebesar 8,5000 , sedangkan nilai ratarata post tes adalah sebesar 11,4000. Besarnya kenaikan atau efektivitas latihan memukul bola yang digantung sebagai berikut:

Tabel 8. Kenaikan Persentase

\begin{tabular}{l|c|c|c}
\hline Kelompok & $\begin{array}{c}\text { Rata- } \\
\text { rata }\end{array}$ & $\begin{array}{c}\text { Perbedaan } \\
\text { Rata-rata }\end{array}$ & Persentase \\
\hline Pre Test & 8.5000 & 3.9 & $18.66 \%$ \\
\hline Post Test & 12.400 & & \\
\hline
\end{tabular}

Berdasarkan tabel di atas, selisih ratarata pos test dengan pretest adalah sebesar 3,9. dari selisih rerata tersebut dapat diketahui kenaikan persentase sebesar $18,66 \%$.

Penelitian ini bertujuan untuk mengetahui pengaruh metode bola gantung dapat meningkatkan kemampuan servis atas putra ekstrakurikuler bolavoli SMK N 3 Kota Begkulu. Hasil penelitian menunjukkan bahwa terdapat pengaruh model latihan bola gantung dapat meningkatkan kemampuan servis atas putra ekstrakurikuler bola voli SMK N 3 Kota Bengkulu. Hal ini dibuktikan dengan nilai signifikansi hitung pada uji $t$ kelompok pretest dan pos test sebesar 0,007 lebih kecil dari 0,05 (Sig<0,05).

Servis atas merupakan bagian paling menarik atau letak seninya dalam permainan bolavoli. Hal ini juga merupakan teknik yang paling sulit untuk dipelajari dari cabang olahraga bolavoli. Untuk melakukan servis atas harus melompat ke udara dan dengan tajam memukul sebuah objek bergerak (bola) dan melewati sebuah rintangan (net) sehingga bola mendarat dalam suatu daerah yang dibatasi (lapangan) (Ervian:2013).

Latihan memukul bola yang digantung dilakukan untuk meningkatkan ketepatan servis atas. Bola digantung yang dimaksud dalam pengertian ini adalah bola yang digantung dengan seutas tali yang diikat pada ujung tiang yang berporos pada pengikat tali, dengan menggunakan bola voli pada ketinggian sesuai dengan jangakauan pemain (Ervian:2013). Latihan memukul bola digantung secara mekanik mampu mengembangkan kecepatan dan ketepatan memukul bola. Dengan awalan langkah serta ketepatan memukul bola yang dilakukan secara berulang-ulang dapat melatih respon memukul bola yang pas dan dapat melatih agar mencapai raihan bola yang tinggi serta lompatan yang tinggi pula.

Pada saat melakukan latihan memukul secara tidak langsung anak melakukan lompatan seperti gerakan pada waktu melakukan servis atas. Sehingga ketika dilakukan tes ketepatan servis atas maka akan mengalami kenaikan. Kenaikan tersebut mencapai $61,81 \%$, merupakan kenaikan yang baik, karena anak baru melakukan latihan sebanyak 16 kali. Anak akan mengalami kenaikan gerak ketika dilakukan latihan sebanyak-banyaknya.

\section{PENUTUP}

Simpulan 
Dalam analisis deskriptif didapatkan kenaikan nilai standar deviasi dari hasil pretest sebesar 4,161 terhadap hasil post-test sebesar 6,012. Hasil uji normalitas di dapatkan nilai Asymp. Sig pre-test dan posttest lebih besar dari 0,05 yang berarti hipotesis diterima. Dalam uji homogenitas didapatkan hasil signifitasi hitung sebesar 0,025 lebih besar dari 0,05 yang berarti hipotesis diterima.

Hasil uji-t diperoleh nilai t hitung $-3,876$ lebih kecil dari 0,05, maka hipotesis diterima. Berdasarkan hasil penelitian yang telah diperoleh dengan analisis dan pengujian hipotesis maka dapat ditarik kesimpulan sebagai berikut: "Terdapat Pengaruh yang signifikan dari model latihan modifikasi bola gantung terhadap kemampuan servis atas putra ekstrakurikuler bila voli siswa SMK N 3 Kota Bengkulu".

\section{Saran}

Setelah melihat kesimpulan dari penelitian ini maka ada beberapa saran yang perlu disampaikan sehubungan dengan hasil penelitian ini, antara lain.

1. Bagi guru, diharapkan memberikan latihan memukul bola yang digantung sesuai dengan kebutuhan supaya siswa memiliki kemampuan servis atas yang baik.

2. Bagi siswa diharapkan melakukan latihan servis atas atau olahraga sendiri dengan mengikkuti kegiatan di luar jam seperti ekstrakulrikuler bola voli.

3. Peneliti berikutnya, agar dapat melakukan penelitian kemampuan servis atas bolavoli dengan mengganti ataupun dengan menambah variabel-variabel yang lain, dan juga memperluas lingkup penelitian.

\section{DAFTAR PUSTAKA}

Arikunto, Suharsimi. (2016). Penelitian tindakan kelas. PT. BumiAksara. Jakarta.

Bompa, T.O, \& Haff, G.G. (2009). Perodization: theory and methodology of trainning. Unites States of America: Human Kinetics.

Beutelstahl Dieter. (2009). Belajar bermain bola volly. Bandung: Pionir Jaya.

Dirto Hadi susanto, Suryati Sidharto, dan Dwi Siswoyo. (1995). Pengantar ilmu pendidikan. Yogyakarta: Fakultas IImu Pendidikan Istitut Keguruan dan IImu Pendidikan.

Erfian Dedy Setyawan. (2013). Pengaruh latihan memukul bola digantung terhadap ketepatan smash peserta ekstrakurikuler bola voli di SMK Tunas Cawas Klaten. Yogyakarta. UNY.

Garcia Ana Marcelina. (2017). Pengaruh Latihan Memukul Bola Gantunng Terhadap Kemampuan Jump Servisce Atlet Putra Club Caroline Kota Lubuk Linggau Provinsi Sumatra Selatan. Bengkulu. UNB

Hidaya Pardijono dkk (2011) Buku Ajar Bola Voli Edisi Keempat.Yogyakarta: FIK UNY.

Janet B. Parks, DA\&Beverly R.K. Zanger. (1990). Sport \& fitness management. USA: Human Kinestics

Nuril Ahmadi. (2007). Panduan olahraga bola Voli. Surakarta: Era Pustaka Utama

PekikDjoko. (2002). Dasar kepelatihan. Yogyakarta: FIK UNY.

Prasetyo, jannah. (2015). Metode penelitian kuantitatif. Jakarta: PT. Raja Grafindo Persada.

Rohmadi Agus. (2010). Perbedaan pengaruh latihan servis atas antara jarak dan tinggi net bertahap terhadap ketepatan servis atas bola voli pada siswa putra ekstrakurikuler SMP Negeri 1 Sidoharjo Kabupaten Sragen tahun ajaran 2009/2010. Surakarta. UNS.

Subroto Toto Amung Ma'mumdan. (2001). Pendekatan keterampilan taktis dalam permainan bola voli konsep dan metode pembelajaran. Jakarta: Depdiknas. Direktorat Jenderal Pendidikan Dasar dan Menengah. 
Sasmita Yusuf Hadi. (1996). Ilmu dasar kepelatihan. Jakarta: Depdikbud: Direktorat Jendral Perguruan Tinggi.

Saputra Prengki (2015) tingkat keterampilan bermain bola pada siswa peserta extrakurikuler SMP Negeri 1 Argamakmur.

Sadiman, Raharjo, Haryono, dan Rahardjito. (2009). Media Pendidikan, Pengertian, Pengembangan, dan Pemamfaatan nya. Jakarta: PT Raja Grafindo Persada.

Sugiyono. (2016) metode penelitian kuantitatif kualitatifdan R\&D. Bandung: Alfabeta.

Viera BarbaraL. Dan Bonie Jill Ferguson. (2004). Bola voli tingkat pemula. Jakarta: PT. Raja Grafindo Persada.

Witono (2017). Buku Pintar Bola Voli. Jakarta Timur: Anugrah. 